\title{
Flexural Performance of Small-Scale Textile-Reinforced Concrete Beams
}

\author{
Fahed Alrshoudi
}

Citation: Alrshoudi, F. Flexural Performance of Small-Scale Textile-Reinforced Concrete Beams. Crystals 2021, 11, 1178. https:// doi.org/10.3390/cryst11101178

Academic Editors: Shunbo Zhao, Juntao Ma and Shan Li

Received: 5 September 2021

Accepted: 22 September 2021

Published: 28 September 2021

Publisher's Note: MDPI stays neutral with regard to jurisdictional claims in published maps and institutional affiliations.

Copyright: (C) 2021 by the author. Licensee MDPI, Basel, Switzerland This article is an open access article distributed under the terms and conditions of the Creative Commons Attribution (CC BY) license (https:// creativecommons.org/licenses/by/ $4.0 /)$.
Department of Civil Engineering, College of Engineering, King Saud University, Riyadh 12372, Saudi Arabia; falrshoudi@ksu.edu.sa

\begin{abstract}
Textile-reinforced concrete (TRC) as a novel high-performance composite material can be used as a strengthening material and component bearing load alone. The flexural performance of TRC beams strengthened with textile reinforcement such as carbon tows was experimentally examined and associated with those of steel-reinforced concrete (SRC) beams. Through four-point bending tests, this research explores the effects of textile layers and dosages of short textile fibre on the flexural strength of concrete beams. A total of 64 prism samples of size $100 \mathrm{~mm} \times 100 \mathrm{~mm} \times 500 \mathrm{~mm}$ were made, flexure-strengthened, and tested to evaluate various characteristics and the efficiency of TRC versus SRC beams. TRC beams performed exceptionally well as supporting material in enhancing concrete's flexural capacity; in addition, TRC's average ultimate load effectiveness was up to $56 \%$ than that of SRC specimens. Furthermore, the maximum deflection was about $37 \%$ lesser than SRC beams. The results showed that by increasing the number of layers, the TRC's effectiveness was significantly increased, and the failure mode became more ductile.
\end{abstract}

Keywords: reinforced concrete; small-scale beams; textile-reinforced concrete; flexural behaviour; carbon fibres

\section{Introduction}

Concrete is considered a brittle material due to its low energy absorption capacity and tensile strength. Structural elements made of concrete, such as beams, are primarily subjected to impacts and bending. Therefore, these components must have increased resistance to deformation and impact loads. Concrete's ability to absorb and distort energy requires additional elements [1-3]. To control cracking, discontinuous fibres are employed inside the concrete, mostly as secondary reinforcement. This is not a replacement technique for the main steel reinforcements [4,5]. Several types of fibres have been utilised to strengthen and rehabilitate RC structural elements for decades. These fibres are strong against corrosion and result in several structural advantages, including lower cover dimensions and, as a result, structural element thickness [6]. According to Tysmans et al. [7], because textile reinforcement has high tensile strength, it might potentially replace steel as the primary reinforcement.

Textile-reinforced concrete (TRC) or textile-reinforced mortar (TRM), a composite material made of high-performance concrete or mortar and textiles fibre, has good corrosion resistance, durability, load-bearing capacity, and ductility. The cover in TRC and TRM is thin owing to textiles' excellent resistance against corrosion $[6,8,9]$. The textile reinforcement is oriented toward tension, enhancing the fibres' utilisation factor [10]. Therefore, TRC is lightweight and can be used in complicated geometrical shapes and arrangements, thin-walled constructions, and prefabricated sandwich panels. It is critical to investigate TRC's mechanical properties thoroughly, particularly its flexural behaviour [11]. Furthermore, incorporating textile fibres in concrete to create TRC has been explored and measured as a novel composite material for applications in buildings [12]. Alkali-resistant textile fibres, such as carbon and glass fibres, are often made up of multi-filament roving. TRC beams provide many benefits over regular fibre-reinforced concrete (FRC) beams, including 
being employed in the presence of stresses [13]. TRC may be utilised entirely in concrete members because it can be situated in essential places, such as following tensile stresses and insufficient amounts.

In contrast, the discontinuous fibre in FRC mixtures is arbitrarily scattered and oriented in the concrete mix, making it less effective. Furthermore, the short fibres are inadequate to regulate fracture development, reinforcement, and strengthening of concrete due to the random arrangement of fibres in traditional FRC mixes. Furthermore, the inclusion of short fibre has a slight effect on beam strength in the compression zone. Textile reinforcement has the same tensile strength as steel reinforcement under tension [14,15].

Fibres are distributed randomly over concrete members, resulting in fibre waste; for example, the fibres allotted to compression zones are not entirely utilised. Consequently, TRC is projected to outperform FRC because the significant difference is the behaviour under strain [16]. Textile reinforcement can be placed where it is desired. Several studies were conducted on the mechanical performance, modelling, and design approach on TRC. Similar to SRC, TRC is regarded as a novel material that might be employed in the architecture and structural sectors because of its high strength and ability to handle large tensile loads $[17,18]$. Researchers discovered that using textile fibres to strengthen concrete components is more efficient and significantly improves structural parts' deformation performance and energy absorption [19]. Häußler-Combe and Hartig [20] found that when concrete is reinforced with textile fibre, the stress-strain trend of TRC beams is comparable to those of SRC beams. However, the TRC has slight, if any, flexibility; consequently, the mode of failure is more brittle, contrasting with the final behaviour seen in most SRC beams. Furthermore, unlike steel bars, the cross-section of the roving textile is non-uniform along the length of the textile reinforcements, according to Hegger et al. [21] and Hartig et al. [22], whereas the cross-section of steel bars is consistently homogeneous.

Furthermore, Hannant [23] observed disparities in post-cracking flexural and uni-axial tensile strengths of FRC beams, emphasising the importance of a thorough understanding of flexure. At post-cracking, the flexural strength is about twice that of the tensile strength. TRC's behaviour, on the other hand, has not been adequately explored, and more data are needed before it can be employed securely. Given the argument, as mentioned above, the purpose of this research was to investigate the effects of textile fibres in various shapes and geometries on the flexural performance of small-scale concrete beams, as well as to figure out how textile fibres contribute to the reduction in crack formation when compared to plain concrete without fibres. Although this study looks into various textile fibres, the tests and analysis are focused on a single type of fibre, multi-filament carbon fibre. Although the research has emphasised the flexural performance of concrete beams under bending loads, it is considered that technical concerns must be addressed and resolved before these fibres can be used as a major reinforcement in concrete beams. This study compared the flexural performance of plain concrete beams to beams reinforced with textile fibres and steel bars using a four-point bending test.

\section{Experimental Program}

\subsection{Materials}

The Portland cement (CEM I) employed in this study has a specific surface area of $3990 \mathrm{~cm}^{2} / \mathrm{g}$ and a specific gravity of 3.15, which fulfils the standard requirements in BS EN 197-1. Fine aggregates that passed through the sieve size of $4.75 \mathrm{~mm}$ were used. Moreover, the crushed quartzitic aggregate was used. It has a specific gravity of 2.7, an irregular form, and a maximum size of $10 \mathrm{~mm}$. Besides, it has $0.50 \%$ water absorption. A polymer-based Superplasticizer was used to help maintain concrete's flowability, delivering a steady dose of $1 \%$ of the binder. Multi-filament carbon fibre (FORMAX, UK) of varying lengths was employed as fibrous reinforced materials in this investigation, and it was then cut into the required lengths according to the beam's size. In this study, the carbon fibres were used, as shown in Figure 1, with a filament diameter of $7 \mu \mathrm{m}$, and a tensile strength of $4000 \mathrm{MPa}$. The engineering properties of textile fibres provided by the supplier are shown in Table 1. 


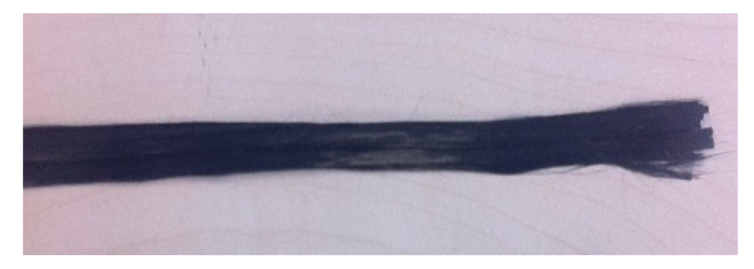

Figure 1. Typical uni-direction carbon textile used as reinforcement.

Table 1. Engineering properties of carbon textile reinforcements.

\begin{tabular}{cc}
\hline Properties & Tow, $\mathbf{5 0 ~ k}$ \\
\hline No. of filaments $(\mathrm{k})$ & 50 \\
\hline Filament diameter $(\mu \mathrm{m})$ & 7 \\
\hline Fabric weight $\left(\mathrm{g} / \mathrm{m}^{2}\right)$ & 130 \\
\hline Modulus of elasticity, $\mathrm{E}_{\mathrm{f}}(\mathrm{MPa})$ & 235,000 \\
\hline Tensile strength, $\mathrm{f}_{\mathrm{f}}(\mathrm{MPa})$ & 4000 \\
\hline
\end{tabular}

\subsection{Concrete Proportions}

The proportions of the plain concrete mix are revealed in Table 2 . To attain the specified strength, all mixtures had a water/cement $(\mathrm{w} / \mathrm{c})$ ratio of 0.35 , and the average compressive strength of conventional concrete was $85 \mathrm{MPa}$ after 28 days of curing. After concrete preparation, fresh concrete was filled up to a depth of $3 \mathrm{~cm}$ into the designed formworks. Then, the textile fibres in the form of reinforcement with the preferred lengths were placed in the beams at the proper positions. After the appropriate placement of textile fibres, the formworks were filled with fresh concrete with appropriate finishing. Besides, the same procedure was used for making SRC beams. After casting, the samples were covered with plastic sheets to avoid evaporation and left for $24 \mathrm{~h}$. Afterwards, the samples were de-moulded and kept in water for a curing period of 28 days.

Table 2. The mixed proportions of plain concrete.

\begin{tabular}{cc}
\hline Concrete Mixture & Mix $\mathbf{( k g / \mathbf { m } ^ { 3 } )}$ \\
\hline Cement & 504 \\
\hline Coarse aggregates & 1108 \\
\hline Sand & 683 \\
\hline Water & 177 \\
\hline w/c & 0.35 \\
\hline Superplasticizer (SP), Litre & 7 \\
\hline Slump Test (mm) & 110 \\
\hline Compressive Strength (MPa) & 85 \\
\hline
\end{tabular}

\subsection{Testing Methods}

The flowability of the fresh concrete mixture was assessed through a slump test, following the specifications of BS EN 12350-2:09. To evaluate the compressive strength of hardened concrete, the $100 \mathrm{~mm}$ cubic specimens were cast and tested in accordance with BS EN 12390:2-09 and BS EN 12390-3:09. The flexural test, which examined the capacity of beams through flexural strength and ductility tests, is the key test in this study. Various reinforcement patterns in TRC beams were evaluated for behaviour and toughness using four-point bending tests. As illustrated in Figure 2, 64 prism samples of size $100 \mathrm{~mm} \times 100 \mathrm{~mm} \times 500 \mathrm{~mm}$ were prepared for flexural strength testing. To calculate the deflection, a LVDT device was placed in the centre of each prism. The test was carried 
out on ToniPACT 3000 testing equipment with a $150 \mathrm{kN}$ capacity and a $0.1 \mathrm{kN} / \mathrm{s}$ loading rate. Some beams had their crack positioning and cracked width specified. The load versus deflection was recorded using a computerised data-gathering device. The loading resolution was $0.01 \mathrm{kN}$, and the deflection resolution was $0.001 \mathrm{~mm}$. The surface of prism specimens was painted white to aid in noticing the initial crack. Besides, to measure the surface strain, DEMEC strain gauges were attached between the two loading sites on the surface of samples. Using an optical microscope, the width of cracks at the bottom of the prisms was also measured.

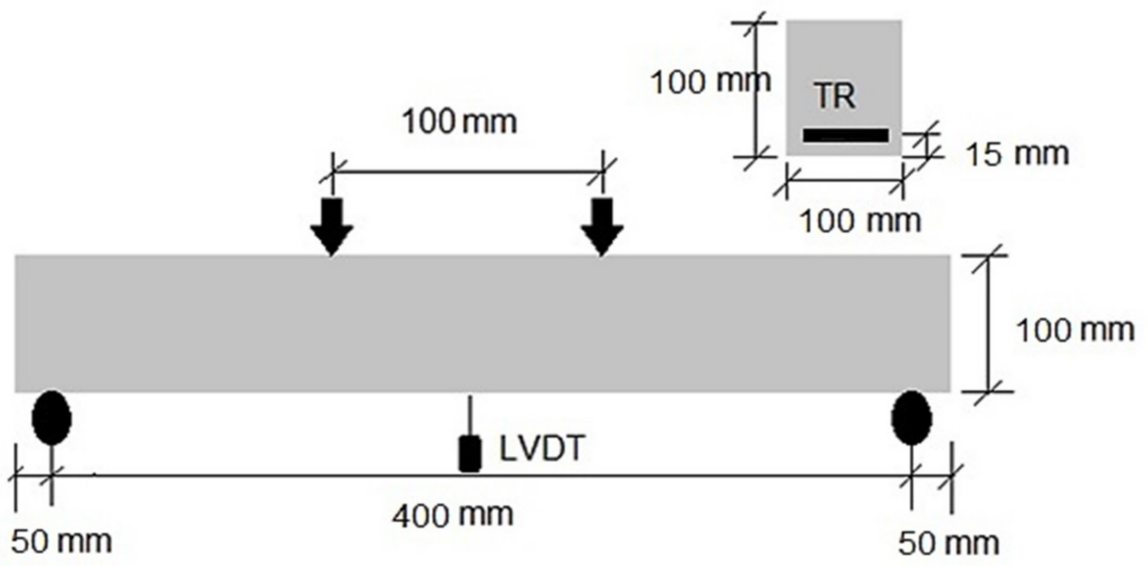

Figure 2. Schematic four-point bending test set-up of small-scale beams.

Weaved fabric and two alternative layouts were employed in bi-axial textile beams. As shown in Figure 3a, the warp textiles were placed in the formworks with the spacing of $5 \mathrm{~cm}$, and the weft textiles were placed with the spacing of $2.5 \mathrm{~cm}$ in all beams. The bi-axial textile was divided into six groups, based on the reinforcement layouts: $\mathrm{BT}_{2}, \mathrm{BT}_{3}$, $\mathrm{BT}_{4}$, and $\mathrm{BT}_{7}$ stand for 2, 3, 4, and 7 layers of fibres over each other, correspondingly, in the warp direction of bi-directional textiles $\left(0^{\circ}\right)$, indicating that the warp rovings resist the load. Furthermore, in the weft direction $\left(90^{\circ}\right)$ of bi-directional textile, $\mathrm{BT}_{2}-90, \mathrm{BT}_{3}-90$, and $\mathrm{BT}_{4}-90$ indicate 2, 3, and 4 layers of fibres. As illustrated in Figure 4, the beams were strengthened in the weft direction, meaning that the weft roving will resist the applied loads, whereas the warp fibres are perpendicular to the loading direction.

Two types of textiles were employed in uni-axial textile beams in two different ways. The first is a tow with $50 \mathrm{k}$ filaments, while the second is a tow with $24 \mathrm{k}$ filaments (twenty thousand filaments). Each layer has four tows with a gap of $2.5 \mathrm{~cm}$ between them (Figure 3b). Besides, $\mathrm{UTb}_{4}, \mathrm{UTt}_{4}, \mathrm{UTc}_{4}$, and $\mathrm{UTbr}_{4}$ stand for four layers of tows with bundled (b), twisted (t), crimped (c), and braided cloth (br), and layered over each other in a uni-axial direction. $\mathrm{UT}_{4}, \mathrm{UT}_{5}$, and $\mathrm{UT}_{7}$ refer to 4,5 , and 7 layers of tows placed on top of each other and laid on the formworks straightly in a uni-axial direction, respectively. Furthermore, uni-axial $24 \mathrm{k}$ reinforcement is separated into two groups: $\mathrm{UTt}_{4}$ refers to four layers of tows twisted and piled on top of each other in a single axis. $\mathrm{UT}_{3}, \mathrm{UT}_{4}$, and $\mathrm{UT}_{8}$ refer to 3,4 , and 8 layers of tows placed on top of each other in a uni-axial orientation, respectively. The concrete beams were also reinforced with discontinuous carbon fibres with a length of $40 \mathrm{~mm}$ to $50 \mathrm{~mm}$. F- $0.62 \%$ and F-1.08\% are the beams with fibre volume fractions of $0.62 \%$ and $1.08 \%$, respectively. Besides, steel bars of $8 \mathrm{~mm}$ diameter were utilised as reinforcement in the SRC beam samples. The beam samples then were tested through the flexural test, and the load-deflection performance was experimentally investigated, and the outcomes of TRC beams were compared with those of SRC beams. 


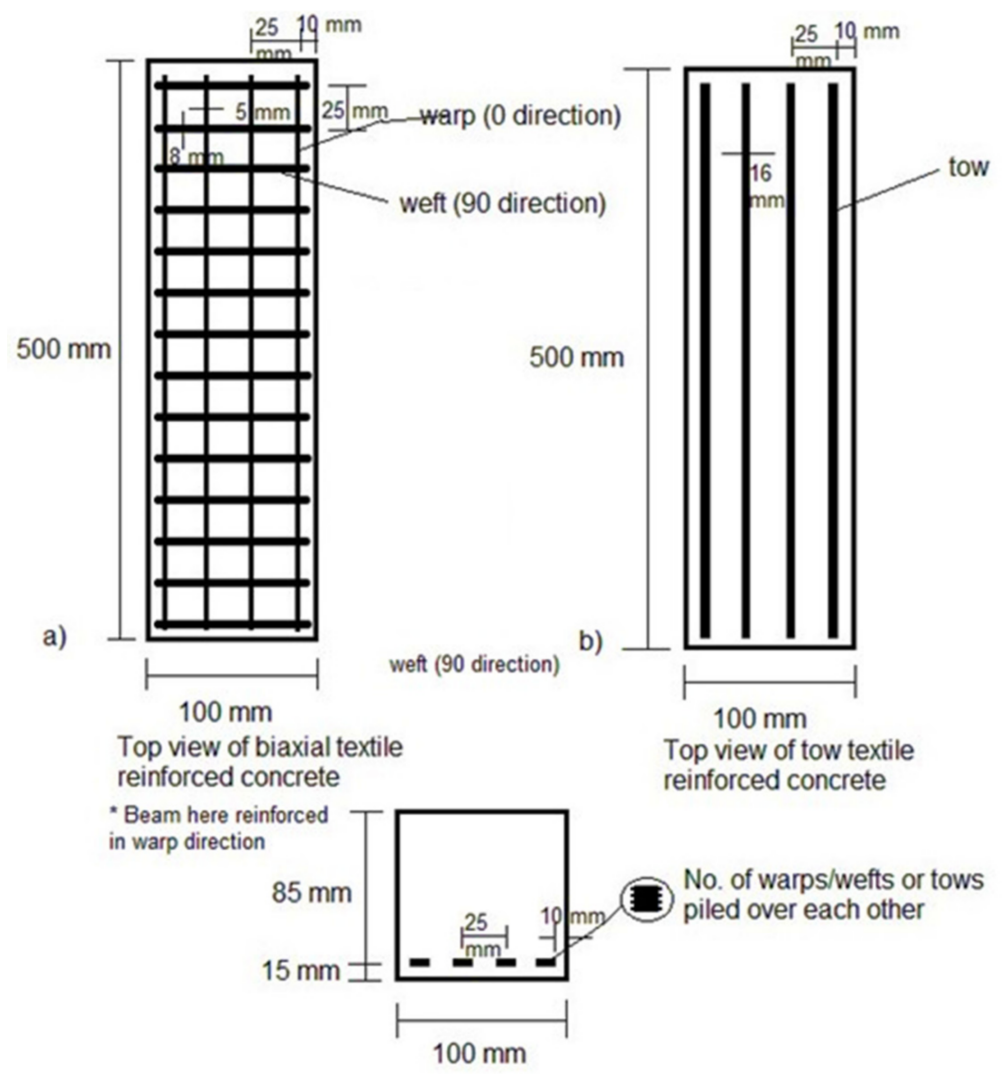

Figure 3. The details of textile reinforcement in (a) bi-axial TRC, (b) tow TRC small-scale beams.

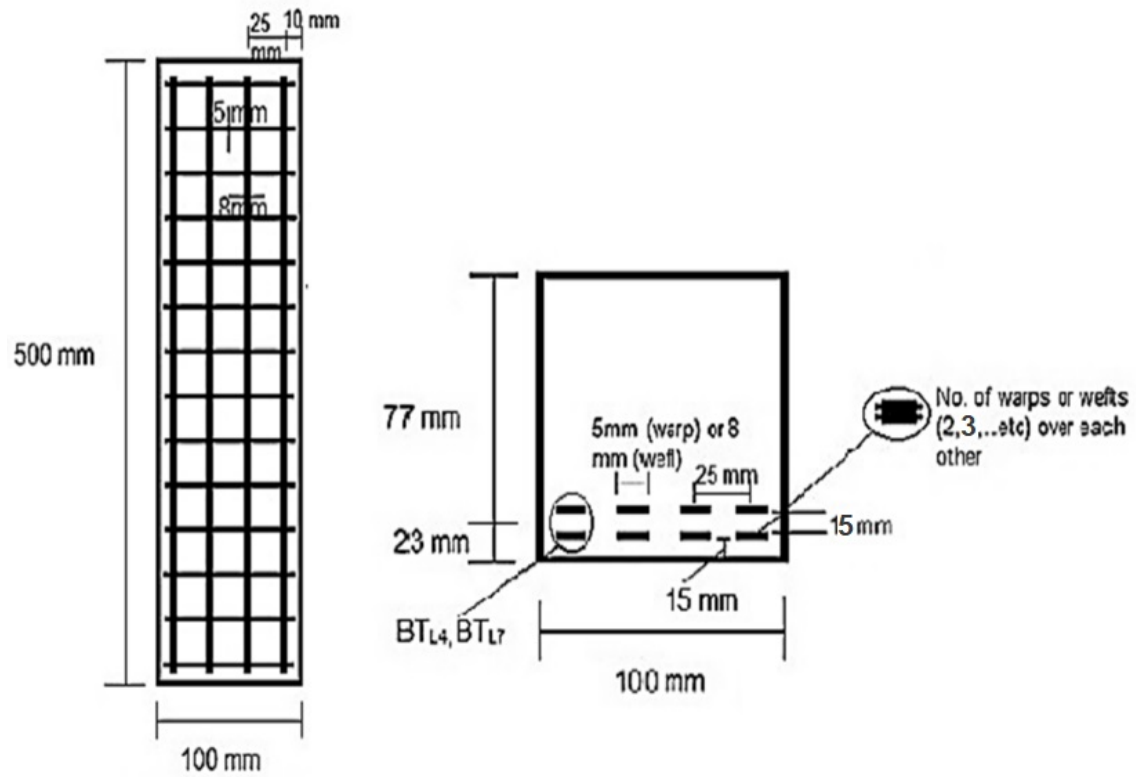

Figure 4. The arrangement of textile fibres in weft direction of small-scale TRC beams.

\section{Results}

\subsection{Unreinforced Concrete Beams}

To see how textile fibres affected load-deflection performance, the failure mechanism, and crack length, researchers used four-point bending to test concrete beams with varied reinforcing schemes, numbers of filaments, and geometries of fibres. To achieve some of the plain concrete qualities, the beams in this group were not reinforced. Two small-scale beams were produced and tested for the control plain concrete beams, and the obtained results are illustrated in Figure 5. Besides, Figure 5 displays the outcomes of four-point 
bending tests on plain concrete beams. It can be observed that the plain concrete beams without fibres obtained the average ultimate deflection of $0.19 \mathrm{~mm}$ for the maximum load of $12.9 \mathrm{kN}$. The lower deflection and load-bearing capacity of beams could be attributed to the brittleness of plain concrete in the absence of textile fibres. Textile fibres in the form of continuous or discontinuous short fibres are generally used in concrete components to enhance the brittle nature of concrete, improve flexural performance, and prevent the sudden failure of concrete beams [2]. However, in the plain concrete beams, the failure modes beams were brittle, and the beam specimens collapsed before the fracture developed, as there were no fibres to bridge the cracks and prevent the sudden failure of beams.

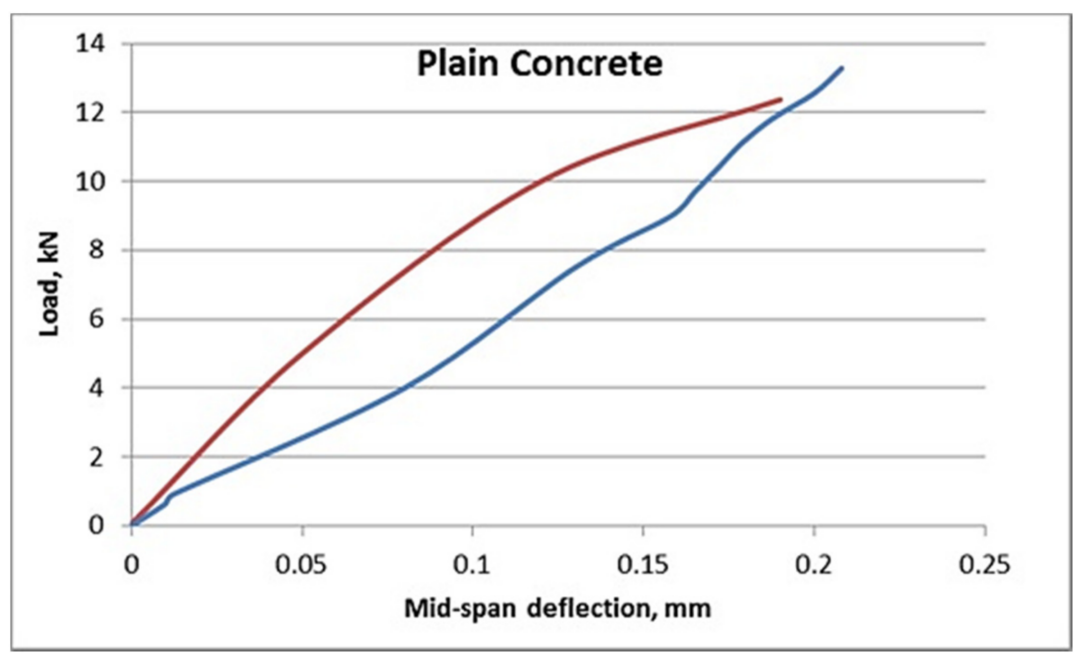

Figure 5. Load-deflection of unreinforced concrete beams at mid-span.

\subsection{Bi-Axial Textile TRC}

The same amount of filaments per roving was utilised in both textiles, but the warp spacing differed. The first has a $2.5 \mathrm{~cm}$ spacing amongst warps, whereas the second has a $5 \mathrm{~cm}$ space between warps. Figures $6-11$ show the results of beams reinforced with a range of $2.5 \mathrm{~cm}$ woven fabric layouts for various layouts and geometries and the performance of diverse numbers of $2.5 \mathrm{~cm}$ woven reinforcements at a warp direction of beams at different fibre dosages. The beams strengthened by a variety of $5 \mathrm{~cm}$ woven fabric arrangements are shown in Figures 12 and 13. The findings reveal that increasing the amount of textile reinforcement in a beam increases its flexural strength and bending capacity. The maximum load of up to $32 \mathrm{kN}$ and a mid-span deflection of $2.5 \mathrm{~mm}$ were recorded for the beams before they failed in the beams reinforced with a more significant percentage of textile fibres, for example, $1 \%$ textile fibres.

The textile reinforcements in the loading direction resisted the generated stresses over the beams and prevented the specimens from failing suddenly when the flexural load was applied. Furthermore, the fibres bridged the cracks and reduced their size, which is the fundamental difference between unreinforced and reinforced beams. According to the findings, the ultimate load and deflection were enhanced as the textile fibre content was increased. These improvements in the performance of bi-axial textile TRC beams over plain beams could be attributed to the bond enhancement and improved penetration due to the reduction in reinforcing congestion [1]. It was also discovered that increasing the number of woven fabrics enhanced the ductility of beams. The behaviour and patterns of fractures in woven fabric with varied geometries and layouts are also depicted in Figure 14 It is clear that increasing the amount of textile fibre in a beam makes it more ductile and minimises fracture breadth. 
Warp (0) Direction
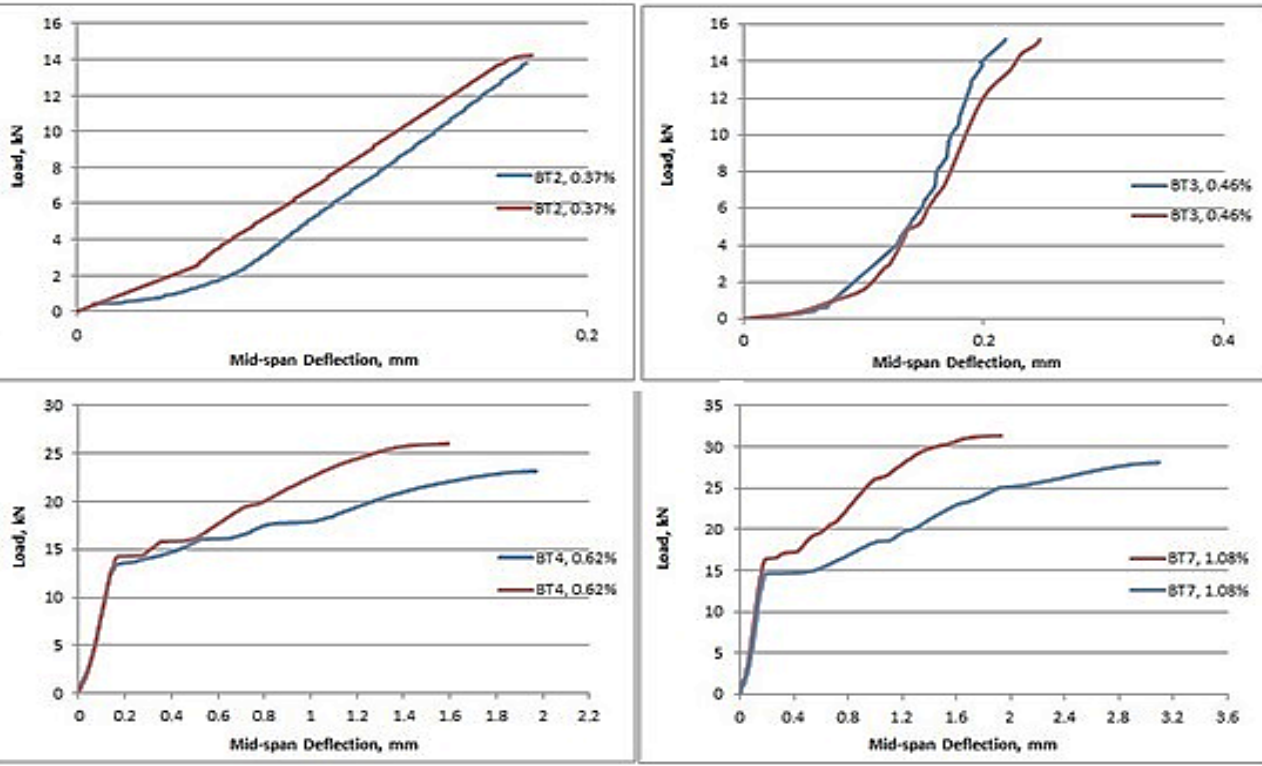

Figure 6. Mid-span load-deflection of TRC beams with woven fabric $(2.5 \mathrm{~cm})$ in the warp direction.
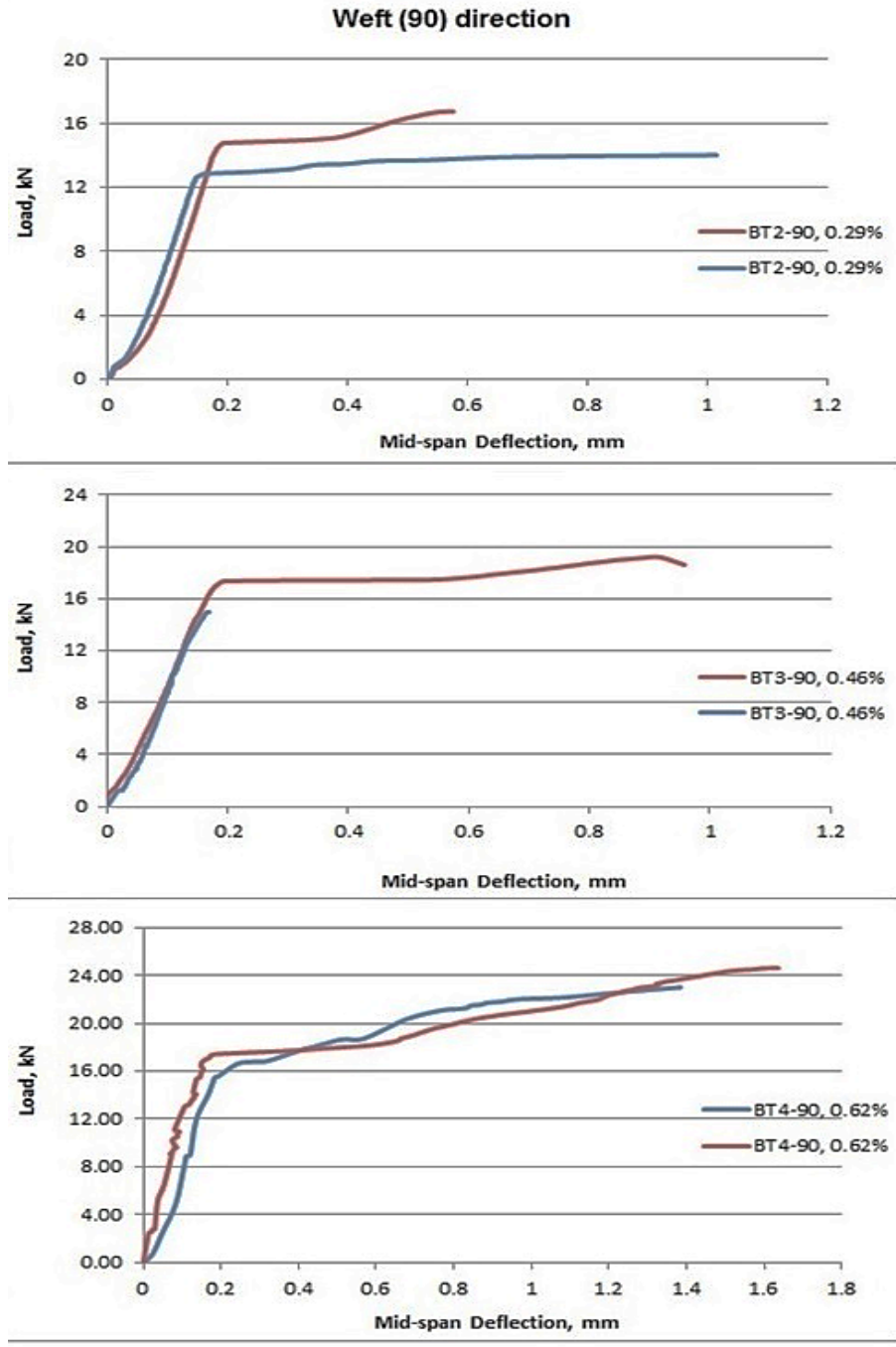

Figure 7. Mid-span load-deflection of TRC beams with woven fabric $(2.5 \mathrm{~cm})$ in the weft direction. 

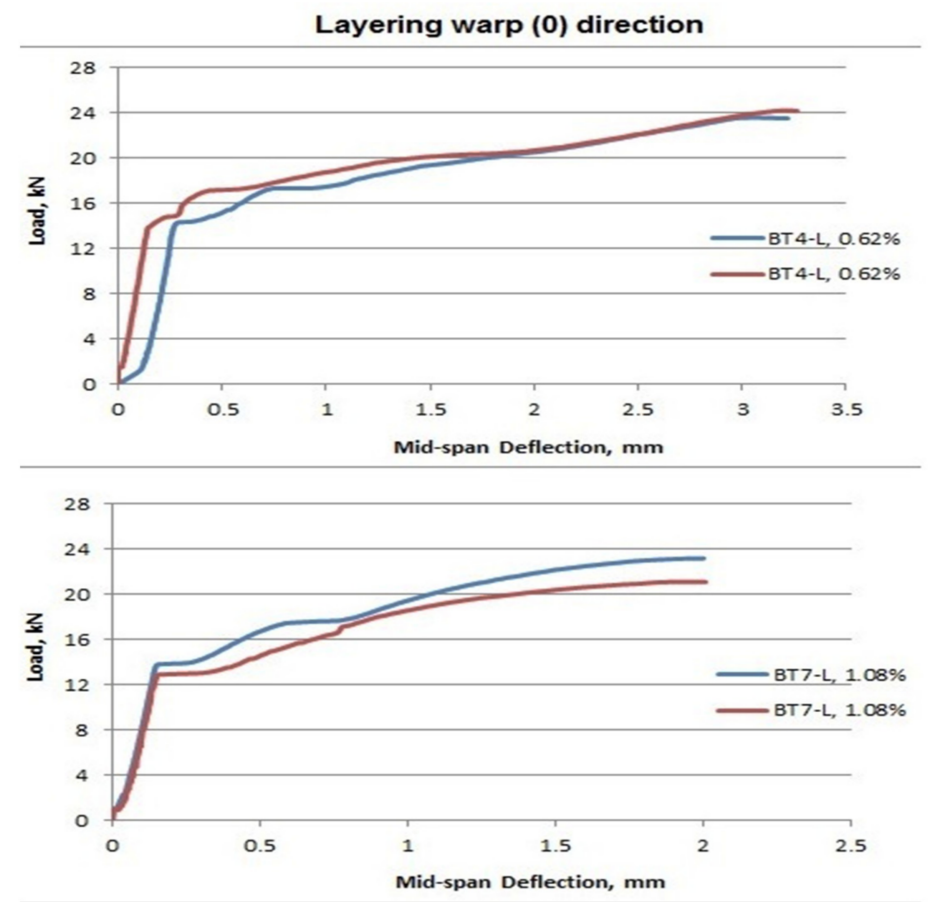

Figure 8. Mid-span load-deflection of TRC beams with various layers of woven fabric $(2.5 \mathrm{~cm})$ at warp direction.
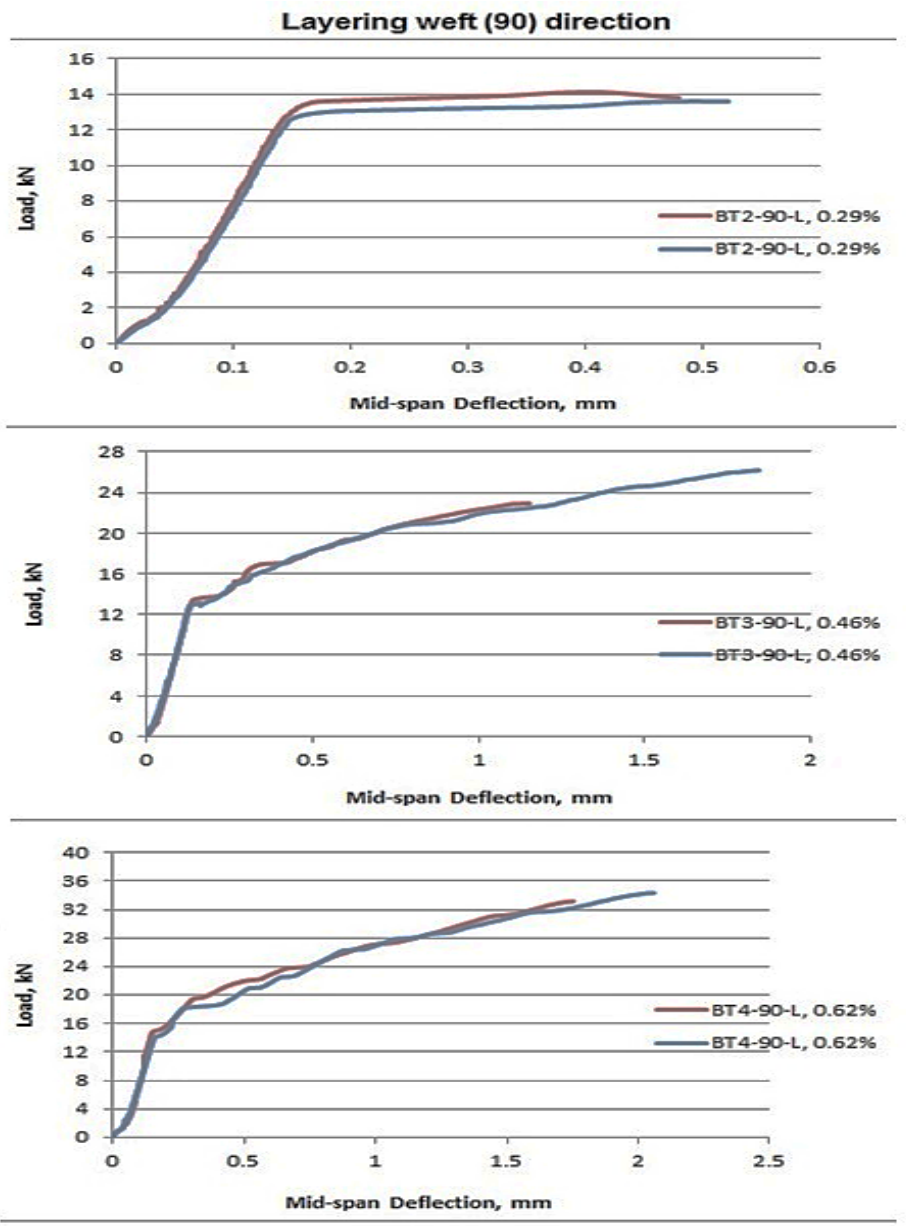

Figure 9. Mid-span load-deflection of TRC beams with various layers of woven fabric $(2.5 \mathrm{~cm})$ at the weft direction. 


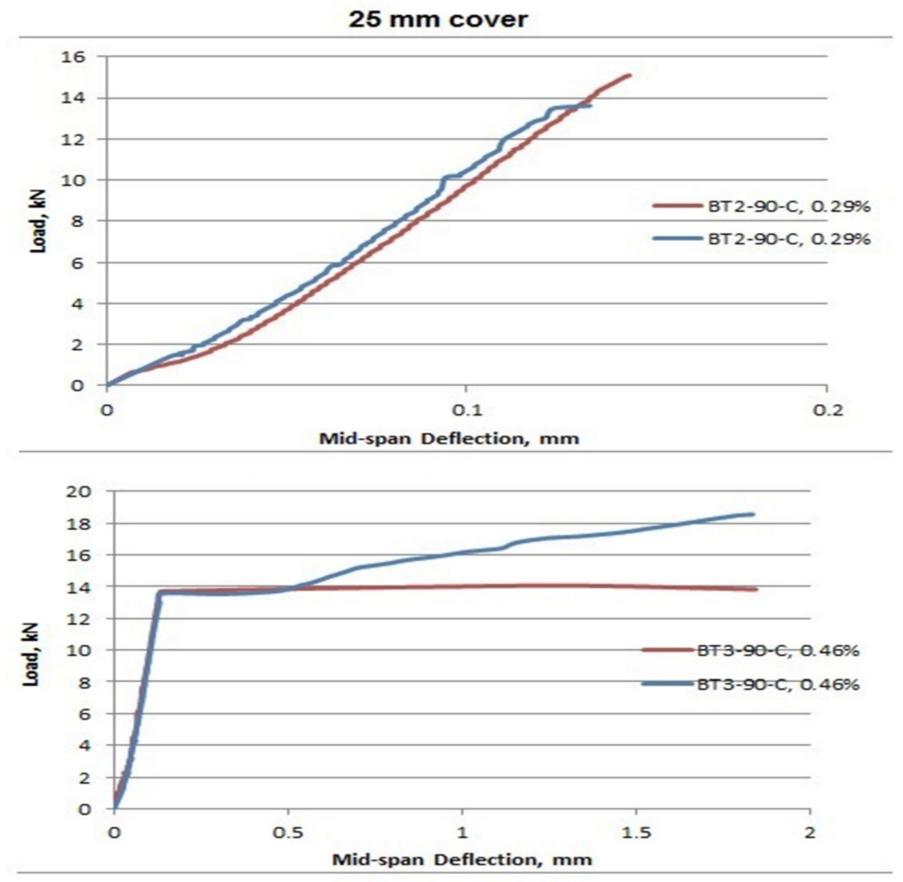

Figure 10. Mid-span load-deflection of TRC beams with woven fabric $(2.5 \mathrm{~cm})$ at the weft direction and $2.5 \mathrm{~cm}$ cover.

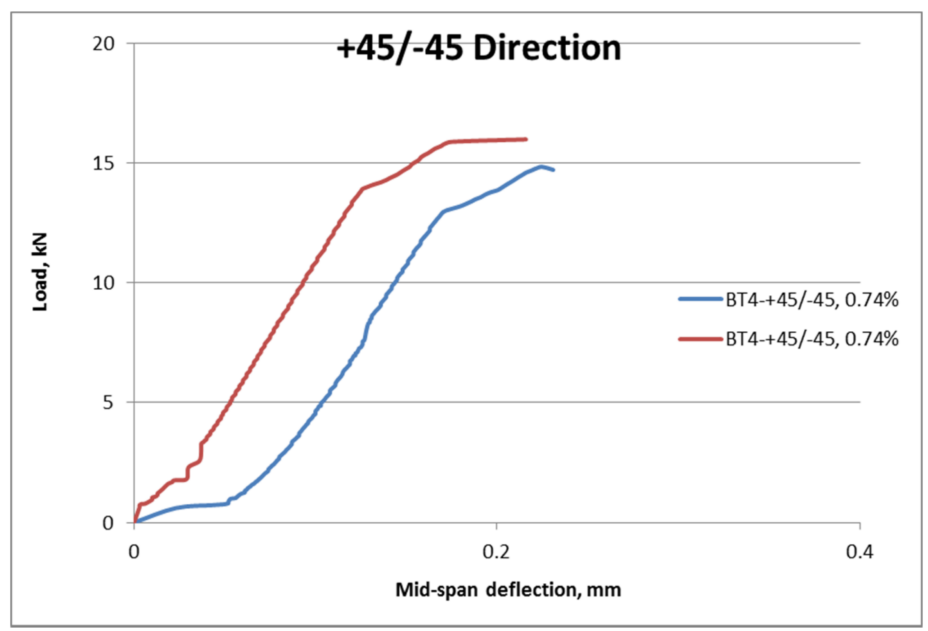

Figure 11. Mid-span load-deflection of TRC beams with woven fabric $(2.5 \mathrm{~cm})$ at $\pm 45^{\circ}$ direction.

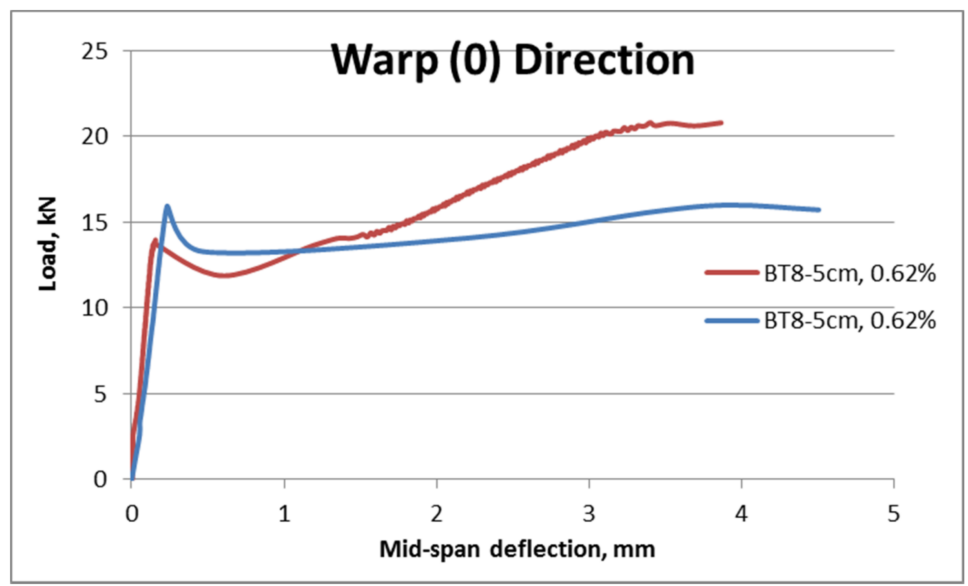

Figure 12. Mid-span load-deflection of TRC beams with woven fabric $(5 \mathrm{~cm})$ at warp direction. 


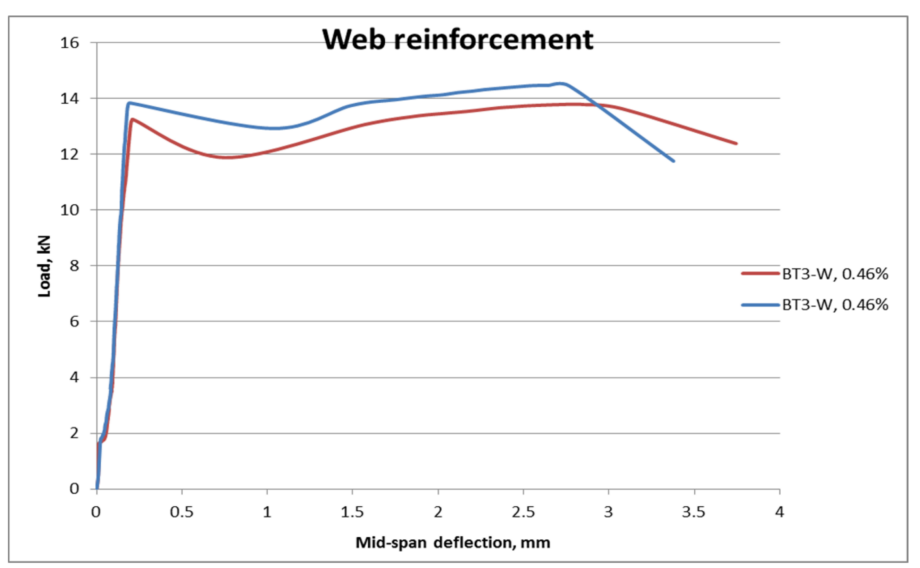

Figure 13. Mid-span load-deflection of TRC beams with web woven fabric $(5 \mathrm{~cm})$ at warp direction.
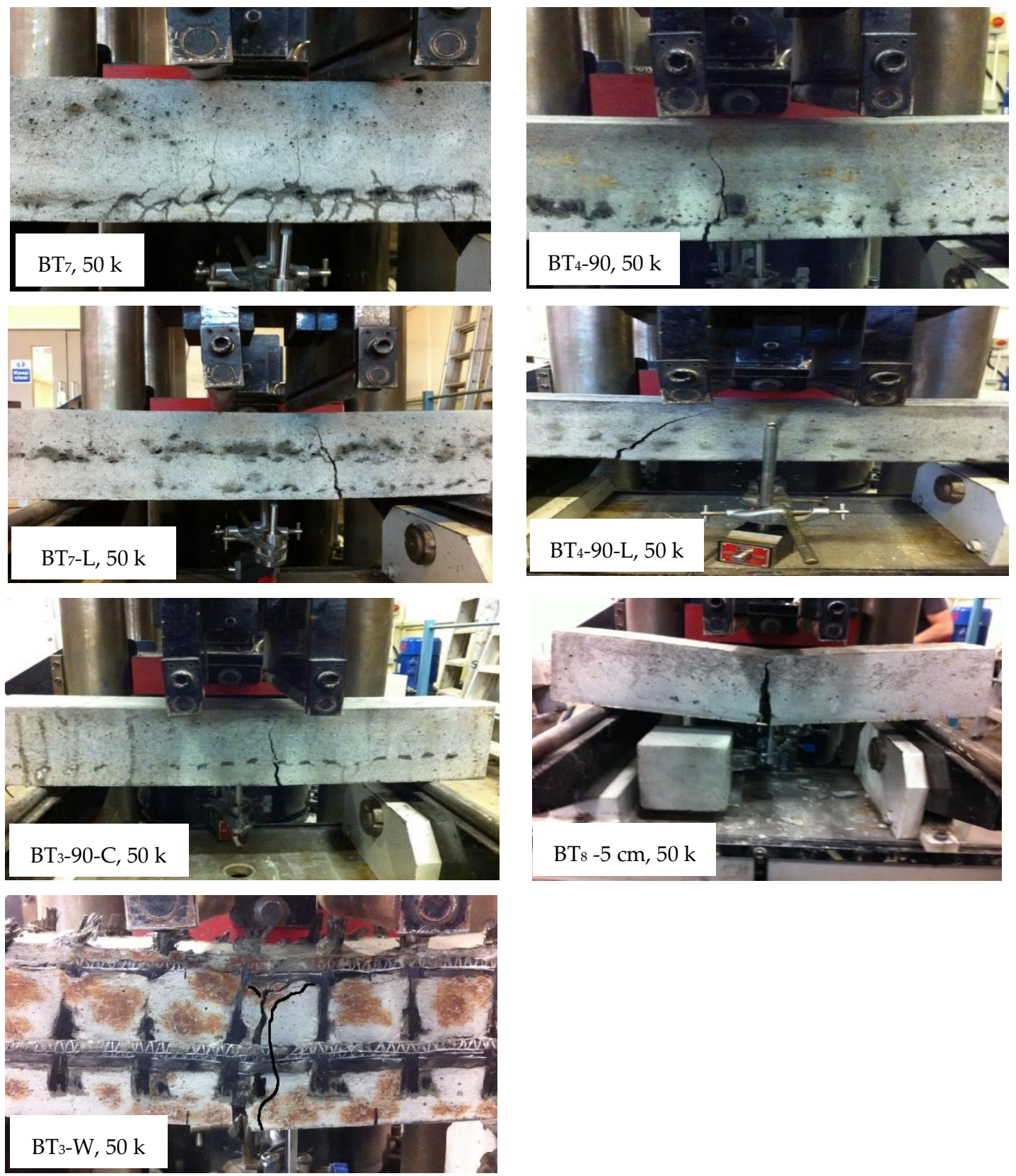

Figure 14. Cracks' pattern of beams reinforced by different bi-axial textiles. 


\subsection{Uni-axial Textile TRC}

Beam specimens were reinforced with $50 \mathrm{k}$ and $24 \mathrm{k}$ filaments of uni-directional tows in this category. Different geometries and layouts were used for each kind. Figures 15 and 16 show the uni-axial tow of different geometries of $24 \mathrm{k}$ and $50 \mathrm{k}$ filament reinforced beams. The load-bearing capacity and deflection improved with the addition of extra reinforcement. Changing the textile geometry also enhanced the capacity during the same effective area. The load capacity of uni-axial textile beams improves with increased mid-span deflection, similar to bi-axial textile beams, as the number of textile layers and content increase.

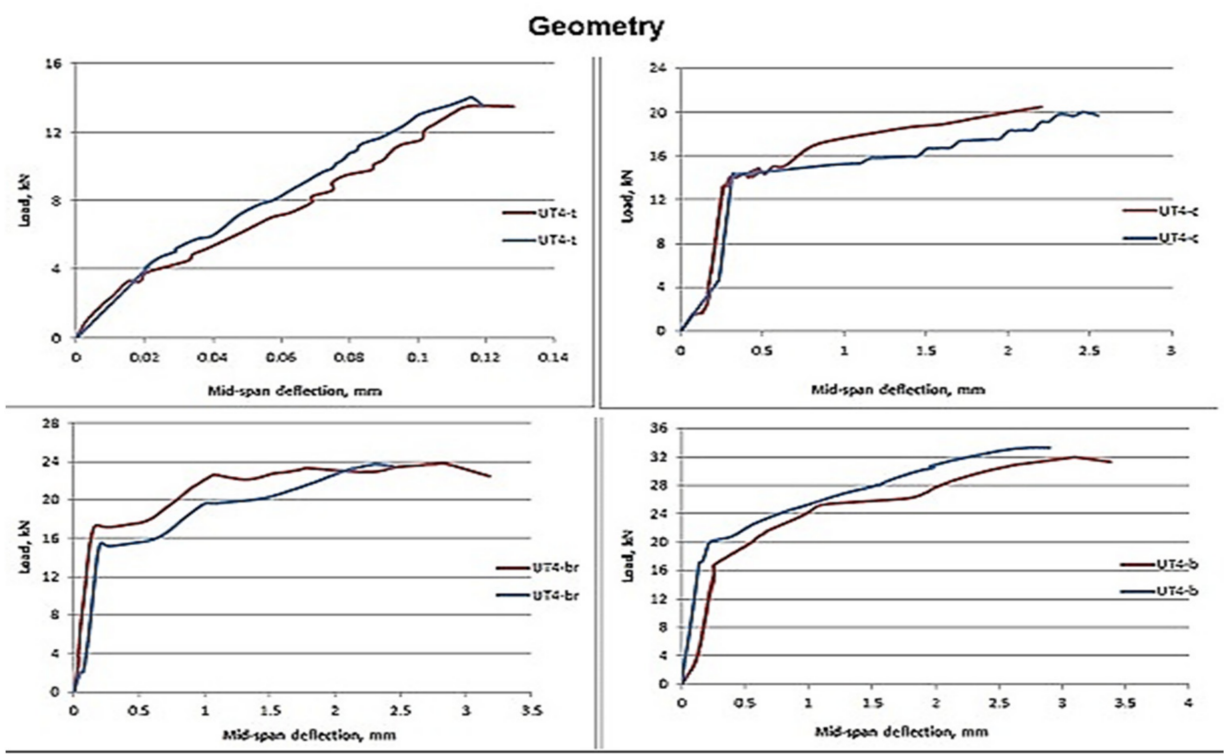

Figure 15. Mid-span load-deflection of uni-axial tows with different geometries and the volume fraction of $0.31 \%$.

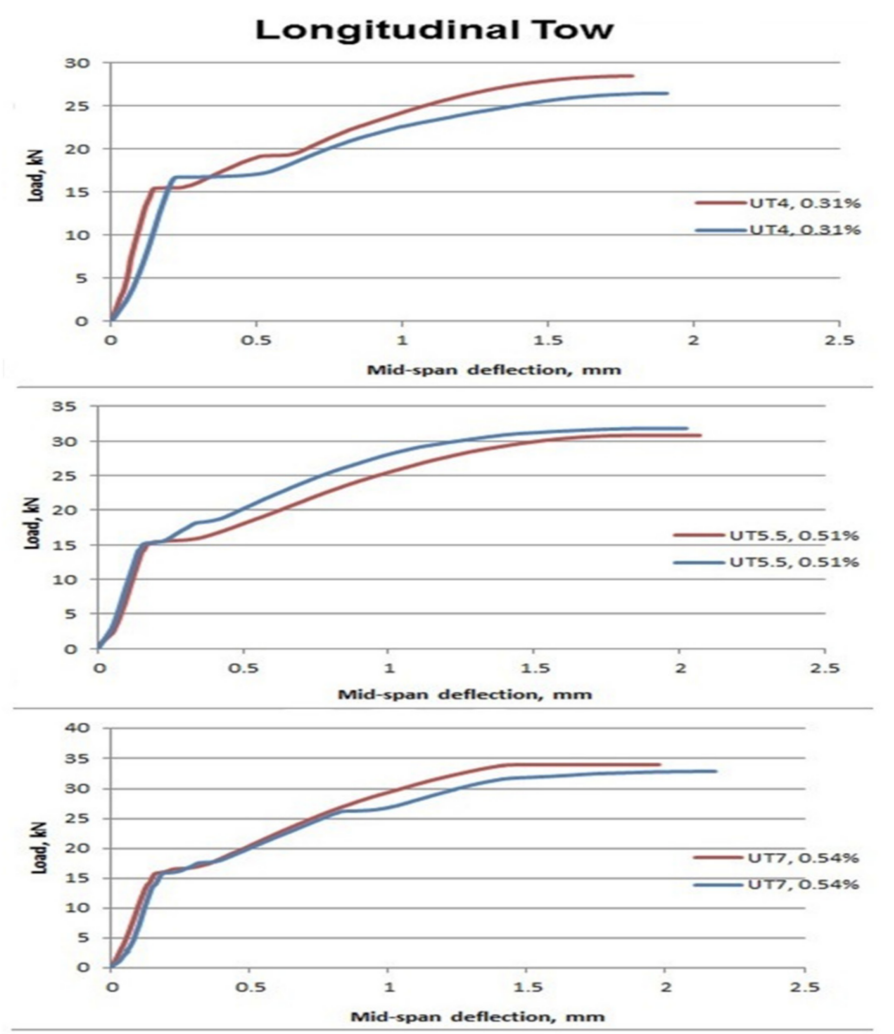

Figure 16. Mid-span load-deflection of uni-axial tows with various fibre volume fractions. 
One of the advantages of textile reinforcement is that, unlike steel reinforcement, it can be easily twisted, braided, or bundled into various shapes. The uni-axial textile TRC beams demonstrated that using longitudinal tows without modifying the geometry considerably increased the average ultimate load. When comparing the ultimate load and deflection of $\mathrm{UT}_{7}$ beams to those of $\mathrm{UT}_{4}$ and $\mathrm{UT}_{5}$ with various fibre doses, it can be noted that the $\mathrm{UT}_{7}$ beams have the highest ultimate load and deflection. This can be explained by the evident increase in the contact area between the matrix and filaments as the reinforcement increases, increasing beam ductility. Figure 17 also depicts the behaviour and fracture patterns of various uni-axial reinforcing geometries and layouts. The failure mechanism of beams is more ductile than that of unreinforced and bi-axial textile beams, as can be seen. Furthermore, the size and number of cracks were significantly reduced.
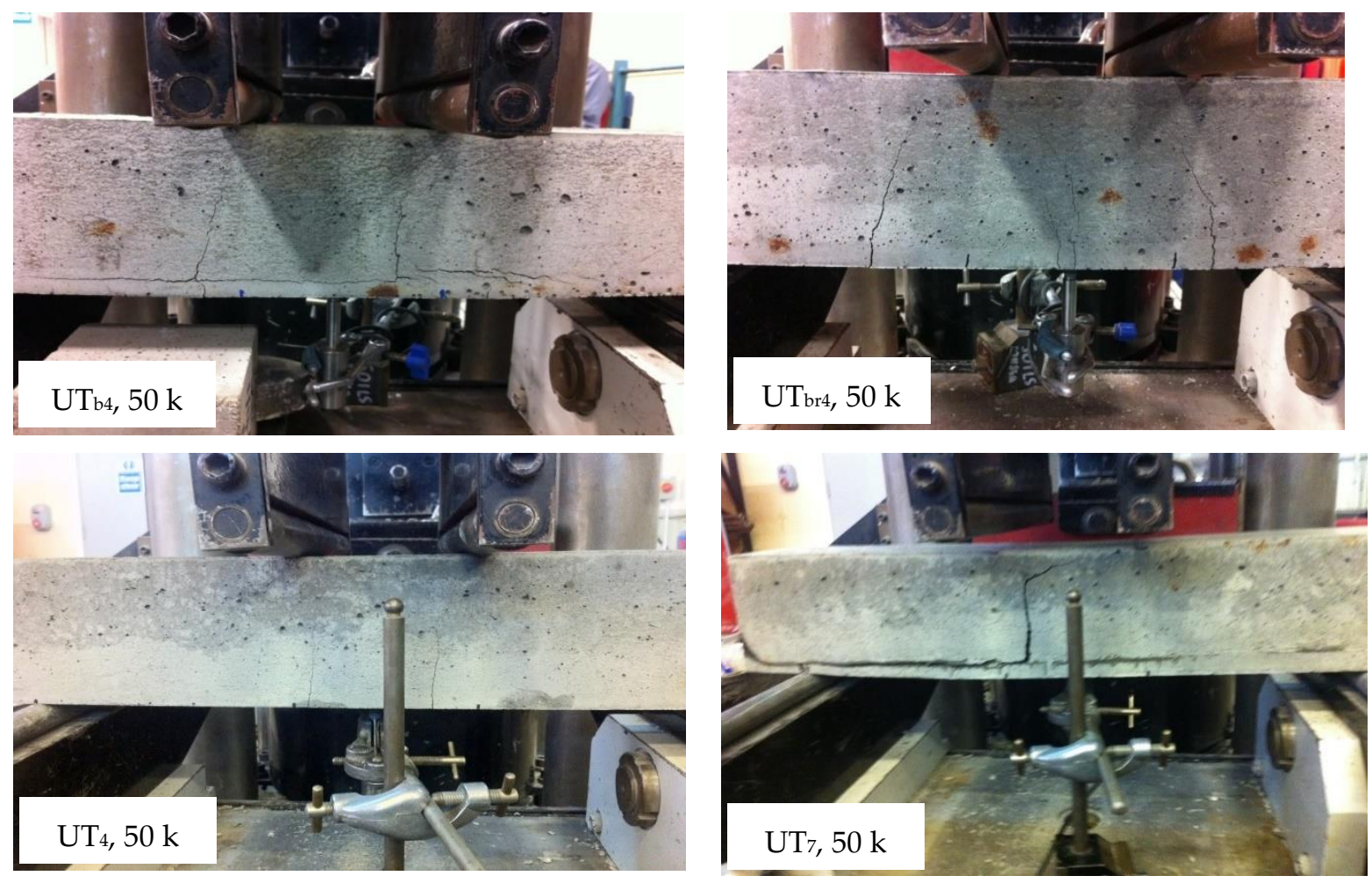

Figure 17. Cracks' patterns of uni-axial TRC beams.

\subsection{Chopped Fibres}

To explore the flexural behaviour of beams and compare it to those reinforced with continuous textile fibres, concrete beams were reinforced with short and discontinuous textile fibres in this category. Figure 18 shows the results of beams reinforced with various fibre volume dosages. The results reveal that chopped fibre has much lower ductility than continuous textile fibres. Similarly, the flexural capacity of beams reinforced with short fibres was lower than that of TRC beams. However, in terms of ductility and load-bearing capability, the flexural performance of these beams was superior to that of plain concrete beams. It can be seen that two different fibre dosages of $0.62 \%$ and $1.08 \%$ were used, and the maximum loads of $14.1 \mathrm{kN}$ and $16.6 \mathrm{kN}$ were recorded, respectively. Obviously, with an increase in the fibre content, the flexural performance of beams was improved. It could be attributed to the bridging action of short fibres, which connect the concrete constituents, prevent cracks, and, therefore, result in higher ductility. Figure 19 also depicts the crack patterns and failure modes of chopped fibre reinforced beams. It can be noticed that the crack width is greater than that of continuous textile fibre reinforced cracks.

Unlike TRC beams, concrete beams reinforced with short fibres are often scattered arbitrarily without regard for the tensile stresses. As a result, the fibres may be placed 
in compression zones or oriented in a direction that is not exposed to tensile pressures; thus, they are not fully utilised. The strength of FRC is unaffected by the presence of short fibres in the compression zones of concrete beams. TRC, on the other hand, is situated at the required stresses, resulting in inefficient use. The ultimate load for TRC is nearly double that of FRC for volume fractions of $0.62 \%$ and $1.08 \%$, indicating that placing the fibre at the appropriate place gives excellent resistance to tensile stresses. In addition, when compared to TRC, the ductility of FRC is noticeably lower. The pull out that occurs in FRC once cracking begins can account for this. In addition, the results show that the volume fraction approach is less accurate than the cross-sectional area approach in determining load-bearing capability.

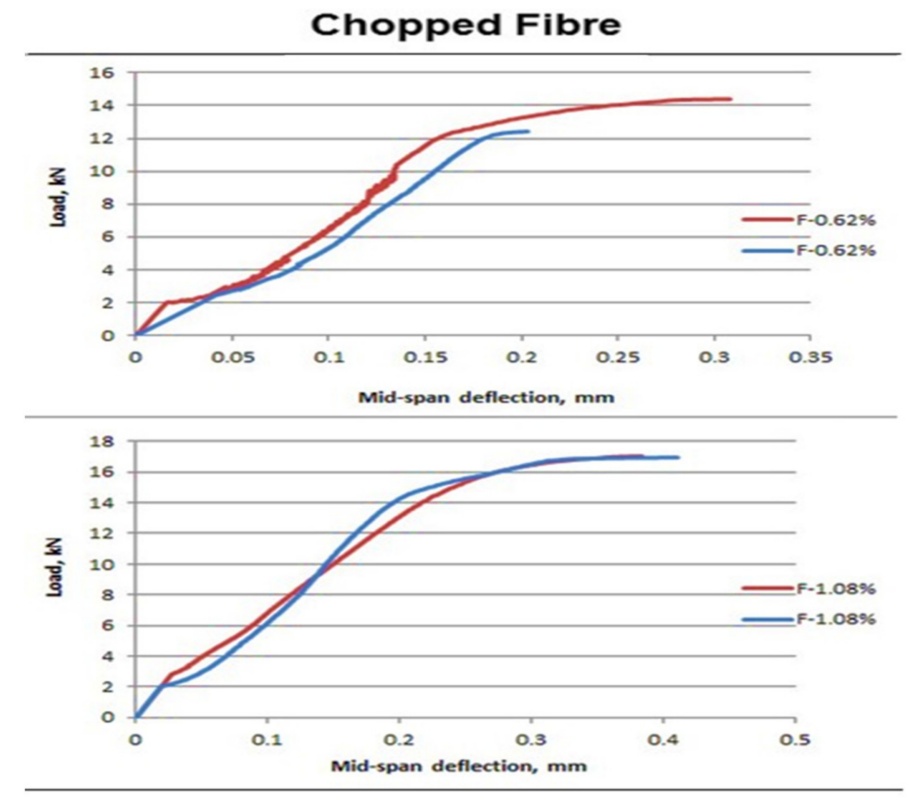

Figure 18. Mid-span load-deflection of short fibres with different fibre dosages.

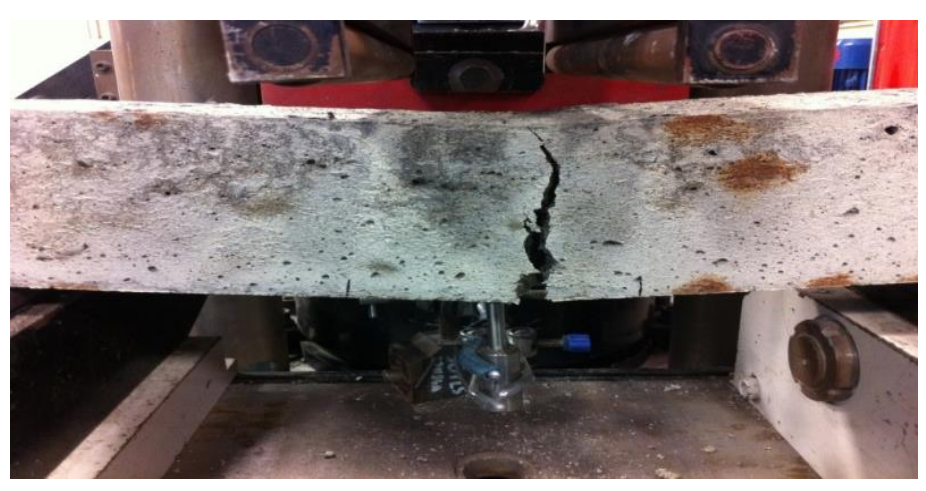

Figure 19. The failure mode of the concrete beam reinforced with $1.08 \%$ short fibres.

\subsection{Steel Reinforced Concrete Beams}

In this study, concrete beams were reinforced with two steel bars of $8 \mathrm{~mm}$ in diameter, which indicates SRC beams. Therefore, to compare and validate the outcomes, the reinforcement area for steel bars was selected to be comparable to the highest cross-sectional area used in TRC beams. Moreover, the same design concept of TRC beams was used for SRC beams to be used as control samples. The findings of SRC beams are revealed in Figure 20. The results revealed that the SRC beams are more ductile with a higher loadbearing capacity and a high mid-span deflection. The average ultimate load of $31.4 \mathrm{kN}$ for SRC beams and the mid-span deflection of $6.4 \mathrm{~mm}$ were recorded. 
The SRC beam deflects more than the TRC beam, as can be observed from the results. In comparison to the steel-reinforced beam, the TRC beam showed less plastic behaviour. The two beams acted similarly before they cracked. The SRC beam started cracking $14 \%$ earlier than the TRC beam. During the cracking creation stage, both beams had the same slope until the steel began to give. The SRC beam had high flexibility at nearly the same stress, whereas the TRC beam curve was still increasing. At the level of the textile reinforcement, two flexural cracks with minor horizontal fissures occurred. A horizontal shear crack developed after the flexural crack. The two cracks widened, and the horizontal crack lengthened largely towards the support as the applied weight was increased. Then, due to the weak link caused by the thin cover thickness and low matrix penetration owing to piling the tows over each other, failure occurred between the textile reinforcement and concrete above the reinforcement.

Consequently, a large number of filaments (inner filaments) were not in contact with the surrounding concrete and hence were not activated to resist any internal stresses. After failure, the textile reinforcement held the beam in place, indicating that the inner filaments were still intact. Accordingly, the behaviour depicted in Figure 21 and the reinforcing mechanism do not indicate genuine ultimate load and deflection. The first crack of the TRC beam, on the other hand, is roughly 15\% higher than the first crack of the SRC beam. The TRC beam slope curve is comparable to the SRC beam under service loads, although it deflects less than the SRC beam. Figure 22 also shows the steel-reinforced concrete crack pattern. The failure mode is more ductile, with tiny cracks, as can be seen.

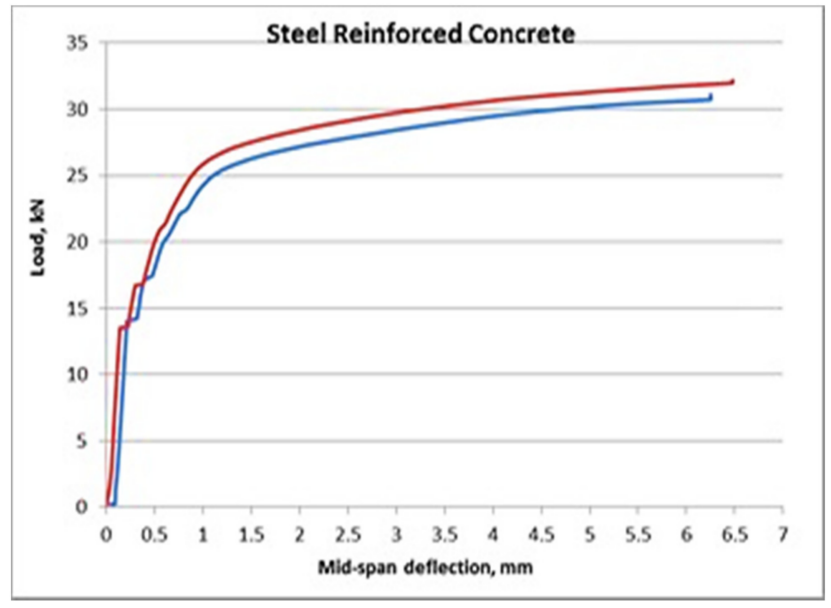

Figure 20. Mid-span load-deflection of the SRC beam samples.

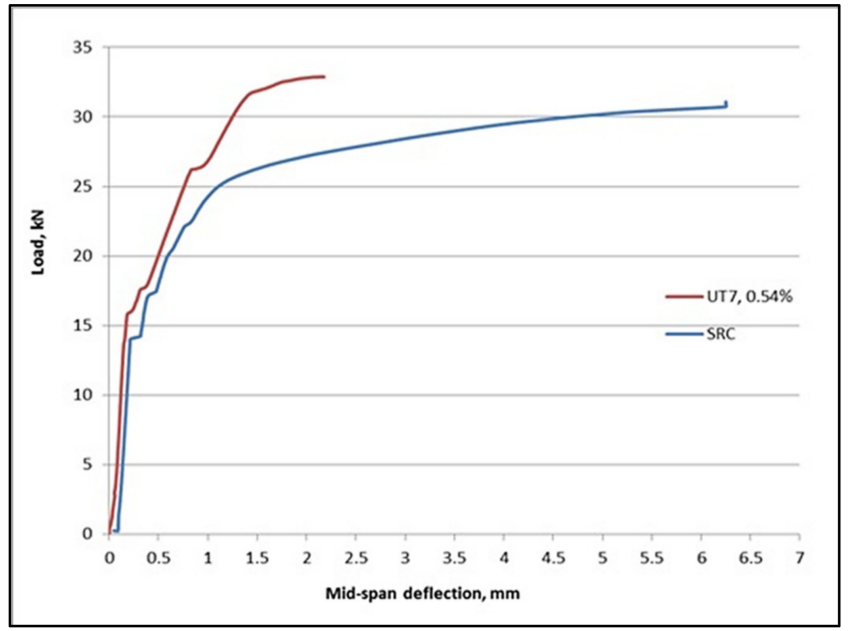

Figure 21. Comparison between mid-span load-deflection uni-axial tow TRC and SRC beams of the same area. 


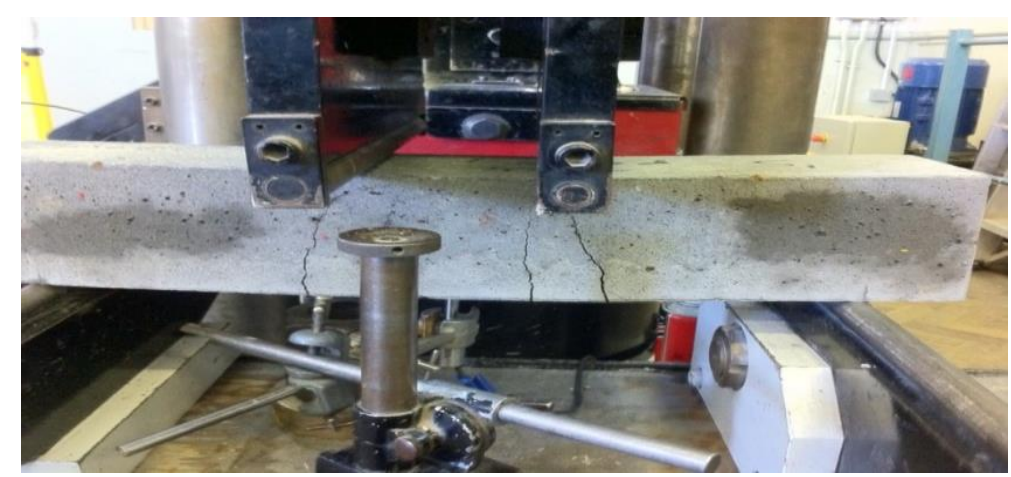

Figure 22. The failure mode and crack patterns of SRC beams.

\section{Discussion}

The voids ratio was first estimated to study the roving densities of the textile. The voids ratio of roving is the ratio of the voids in the cross-sectional area to the area of the roving's cross-section. Due to the increase in voids, a rise in the ratio leads to a surge in diffusion. As a consequence, the effect of increasing or decreasing the roving's width may be measured. The voids ratio may vary for the same number of filaments owing to differences in the roving's cross-sectional area (warp, weft, or tow). Therefore, Equation (1) was used to compute the void ratios:

$$
\rho_{v}=\frac{A_{g}-A_{f}}{A_{g}}
$$

where $\rho_{v}$ indicates the void ratio; $A_{f}$ is the area of filaments multiplied by the number of filaments in the tow or roving; $A_{g}$ is the cross-sectional area of the roving textiles, including the voids.

The results revealed that the voids ratio increased with the rise in the roving's crosssectional area for the same number of filaments. This indicates that the filaments have been condensed, resulting in the roving being smaller and having less surface area than the matrix. There are precisely the same number of fibres in both directions of the bi-axial textile to reinforce the concrete beams. Weft-to-warp voids ratios are lower because the filaments are sewed in warp-to-weft directions. Table 3 demonstrates that reinforcing in the weft direction has no significant effect compared to the warp direction. The voids ratios between warp and weft are very similar, which could explain the capacity comparability. In $\mathrm{UT}_{4}$, however, increasing the voids ratio leads to a rise in load capacity. When compared to $\mathrm{BT}_{4}$, the load strength improved by $12 \%$, but the ductility remained unchanged. Accordingly, raising the voids ratio is beneficial since it increases load capacity while retaining ductility.

Table 3. Voids ratio and average ultimate load and deflection of bi-axial textile TRC beams.

\begin{tabular}{|c|c|c|c|c|c|}
\hline Reinforcement & Area $\left(\mathrm{mm}^{2}\right)$ & $V_{f}(\%)$ & Voids Ratio & Average Ultimate Load (kN) & Average Deflection (mm) \\
\hline $\mathrm{BT}_{3}, 50 \mathrm{k}$ & \multirow{2}{*}{23.1} & \multirow{2}{*}{0.46} & 0.61 & 15.2 & 0.2 \\
\hline $\mathrm{BT}_{3}-90,50 \mathrm{k}$ & & & 0.65 & 16.9 & 0.6 \\
\hline $\mathrm{BT}_{4}, 50 \mathrm{k}$ & \multirow{2}{*}{30.8} & \multirow{2}{*}{0.62} & 0.61 & 24.6 & 1.8 \\
\hline $\mathrm{BT}_{4}-90,50 \mathrm{k}$ & & & 0.65 & 24 & 1.5 \\
\hline $\mathrm{UT}_{4}, 50 \mathrm{k}$ & 30.8 & 0.31 & 0.76 & 27.5 & 1.9 \\
\hline
\end{tabular}

Furthermore, the effect of changing the orientation of the textile reinforcements with the loading direction on TRC behaviour was examined. The reinforcement was placed in $\pm 45^{\circ}$ different directions. The average findings of $45^{\circ}$ TRC are shown in Table 4 . The results show that a noteworthy reduction in the reinforced beam capacity occurs 
when the loading direction is changed. According to Hegger et al. [24], the ultimate load reduces as the angle of reinforcement surges. According to the data, the ultimate load decrease from placing the textile reinforcements at $45^{\circ}$ is $38 \%$. According to their findings, a $45^{\circ}$ orientation reduces the load-bearing capacity of carbon fibre reinforced concrete by $60 \%$. The rise in load capacity seen in this study is due to a surge in active filaments [25]. In addition, the deflection of the ductility decreased by $89 \%$. Because of the discontinuity in the textile in this example, the deflection and bending moment strength reveal that the textile reinforcements at $45^{\circ}$ operate similarly to chopped fibre. This could account for the lower ultimate load and deflection. Consequently, the deviancy of textile reinforcements from the loading directions results consequently in a considerable decrease in the reinforced beam's capacity.

Table 4. Ultimate loads and deflections of $\pm 45^{\circ}$ TRC beams.

\begin{tabular}{ccccc}
\hline Reinforcement & Area $\left(\mathbf{m m}^{2}\right)$ & $\mathbf{V}_{\mathbf{f}} \mathbf{( \% )}$ & $\begin{array}{c}\text { Average Ultimate } \\
\text { Load (kN) }\end{array}$ & $\begin{array}{c}\text { Average } \\
\text { Deflection }(\mathbf{m m})\end{array}$ \\
\hline $\mathrm{BT}_{4}, 50 \mathrm{k}$ & \multirow{2}{*}{30.8} & 0.62 & 24.6 & 1.8 \\
\cline { 1 - 2 } $\mathrm{BT}_{4}-+45 /-45,50 \mathrm{k}$ & & & 15.3 & 0.2 \\
\hline
\end{tabular}

Table 5 also shows the effect of a rise in the number of woven textile layers and filaments on the performance of TRC beams. This is in line with Yin, Lü, and Xu [26], who discovered that increasing the number of textile layers does not affect the stiffness of textile reinforced beams before cracking but does improve the stiffness after cracking. However, a deeper examination reveals that the percentage rise for many rovings at the same layer is relatively low compared to a lesser one. For instance, when a small number of rovings are present at the same stratum, $\mathrm{BT}_{4}$ outperforms $\mathrm{BT}_{3}$ by $63 \%$. At $\mathrm{BT}_{4}$, however, there is simply one more layer (a 33\% increase in area). The ratio of growth in the strength to rise in the area is said to be high. Because $\mathrm{BT}_{3}$ 's ultimate strength is small, there is a visible difference between $\mathrm{BT}_{3}$ and $\mathrm{BT}_{4}$. Compared to $\mathrm{BT}_{4}$, with a rise in the number of layers of textile fibres by three in $\mathrm{BT}_{7}$ beams, the ultimate strength increased by about $21 \%$.

The improvement does not reflect the area's percentage gain. Consequently, having more woven fabrics increases the ultimate loads. It can be explained by a rise in the inner filaments of the woven fabrics, which are not effectively used as reinforcement, as evidenced by the rise in the $\mathrm{BT}_{7}$ deflection due to internal filament slippage. Owing to piling up the rovings, the contact area of $\mathrm{BT}_{7}$ diminishes as the number of woven textiles increases [27]. Notably, the outside filaments have a larger contact area, albeit a smaller one than the internal filaments, which have a smaller contact area. Consequently, some internal warp rovings that resist load are effectively deactivated when applied load is applied; yet, they give ductility due to filament sliding. Furthermore, due to the congestion caused by the stacking of the textiles, the placement of concrete in the formworks is more complicated.

Table 5. The effects of rovings at the same layer on the ultimate loads and deflections of TRC beams.

\begin{tabular}{ccccc}
\hline Reinforcement & Area $\left(\mathbf{m m}^{\mathbf{2}}\right)$ & $\mathbf{V}_{\mathbf{f}}(\mathbf{\%})$ & $\begin{array}{c}\text { Average Ultimate } \\
\text { Load } \mathbf{( k N )}\end{array}$ & $\begin{array}{c}\text { Average } \\
\text { Deflection }(\mathbf{m m})\end{array}$ \\
\hline $\mathrm{BT}_{2}, 50 \mathrm{k}$ & 15.4 & 0.37 & 14.2 & 0.2 \\
\hline $\mathrm{BT}_{3}, 50 \mathrm{k}$ & 23.1 & 0.46 & 15.2 & 0.2 \\
\hline $\mathrm{BT}_{4}, 50 \mathrm{k}$ & 30.8 & 0.62 & 24.6 & 1.8 \\
\hline $\mathrm{BT}_{7}, 50 \mathrm{k}$ & 53.9 & 1.08 & 29.7 & 2.6 \\
\hline
\end{tabular}

In addition, the study looks at how the weft rovings might affect TRC behaviour. Therefore, the same bi-axial textile reinforcement features were used in the uni-axial direction. Table 6 presents the ultimate loads and deflections of bi-axial and uni-axial TRC 
beam samples. It is clear from the data that the influence of weft roving on the load-bearing capacity is negligible. The average ultimate load is improved in both situations, $\mathrm{UT}_{4}$ and $\mathrm{UT}_{7}$, respectively, compared to $\mathrm{BT}_{4}$ and $\mathrm{BT}_{7}$. The rovings in the loading path effectively resisted the stresses caused by the bending under flexural load [28]. The bond enhancement and penetration improvement owing to the reduction in reinforcing congestion can explain these findings. Furthermore, tow reinforcement has a larger perimeter than bi-axial reinforcement warp rovings. The tow width of the bi-axial textiles was $16 \mathrm{~mm}$, whereas the warp width was about $5 \mathrm{~mm}$. Due to the slipping inner filaments, the beams of bi-axial reinforcements with high quantities of woven textiles $\left(\mathrm{BT}_{7}\right)$ were revealed to be more ductile in nature than those with lower numbers of woven textile beams.

Table 6. The effects of numbers of woven textiles on the load and deflection of uni- and bi-axial TRC beam samples.

\begin{tabular}{|c|c|c|c|c|}
\hline Reinforcement & Area $\left(\mathrm{mm}^{2}\right)$ & $V_{f}(\%)$ & $\begin{array}{l}\text { Average Ultimate } \\
\text { Load }(\mathrm{kN})\end{array}$ & $\begin{array}{c}\text { Average } \\
\text { Deflection }(\mathrm{mm})\end{array}$ \\
\hline $\mathrm{BT}_{4}, 50 \mathrm{k}$ & \multirow{2}{*}{30.8} & 0.62 & 24.6 & 1.8 \\
\hline $\mathrm{UT}_{4}, 50 \mathrm{k}$ & & 0.31 & 27.5 & 1.9 \\
\hline $\mathrm{BT}_{7}, 50 \mathrm{k}$ & \multirow{2}{*}{53.9} & 1.08 & 29.7 & 2.6 \\
\hline $\mathrm{UT}_{7}, 50 \mathrm{k}$ & & 0.54 & 32.9 & 2.1 \\
\hline
\end{tabular}

Several researchers have looked at the mechanical properties of TRC [22,29-31]. However, fibre dosages were used to express the consequence of the increase in fibre content on the mechanical performance of concrete. In this regard, Abdulmajeed et al. [32] discovered that a rise in fibre content does not always imply an improvement in the composite's flexural strength. As a result, it appears that using volume fraction as a design criterion could lead to inefficient outcomes. When using fibre dosage methods, all the fibres in the concrete member are considered, no matter how they are oriented. Because some of the fibres in TRC, such as those that act perpendicular to the beam's span and those in the central part of the batch of fibres, are not used in stress resistance, this technique could be profoundly incorrect. Table 6 displays the findings for various fibre dosages on the ultimate loads of beams with the same dimensions. As can be observed, the increasing volume has a negligible effect on improving ultimate load. $\mathrm{BT}_{4}$ has a volume fraction of $0.62 \%$, and $\mathrm{UT}_{4}$ has a volume fraction of $0.31 \%$; nevertheless, the flexural loads remain unchanged despite doubled volume fraction.

On the other hand, a further rise in the fibre content reduced the flexural loads, owing to the lower flowability of concrete and improper placement in formworks. It can be seen that with the rise in fibre content in the same dimension beams of $\mathrm{BT}_{7}$ and $\mathrm{UT}_{7}$, the ultimate flexural loads decreased by about $1.08 \%$ and $0.54 \%$, respectively. Consequently, it appears that the ultimate load in FRC beams is not linearly related to the fibre dosages. As previously stated, utilising a volume fraction-based technique in TRC may result in improper design. Table 6 shows that the rise in textiles was primarily responsible for improving the ultimate load. A rise in fibre dosage appears to indicate a surge in failure load at first glance. The ultimate load rises from $27.5 \mathrm{kN}$ to $33.5 \mathrm{kN}$ in $\mathrm{UT}_{4}$ beams with $\mathrm{V}_{\mathrm{f}}=0.31 \%$ and $\mathrm{UT}_{7}$ beams with $\mathrm{V}_{\mathrm{f}}=0.54 \%$. However, a deeper examination of these outcomes reveals that the alignment of the fibres is more important than the total fibre content, and the cross-sectional area technique is better for determining this and the ultimate load $[33,34]$.

For example, in TRC beams of $\mathrm{BT}_{4}$ and $\mathrm{UT}_{7}$, the ultimate loads were increased by about $75 \%$ and $36 \%$, respectively, with a reduction in fibre dosages and a surge in the crosssectional area of fibres. Moreover, the ultimate flexural loads were found to be different in BT4 and UT4 beams with the same fibre area of $30.8 \mathrm{~mm}^{2}$ and fibres' dosages of $0.62 \%$ and $0.31 \%$. Consequently, in the design methodology of beams, the method of cross-sectional area-based is preferable and must be addressed $[35,36]$. Besides, the fibre dosage parameter 
is more appropriate for usage with short and randomly dispersed fibres in concrete, where the exact cross-sectional area of fibres cannot be estimated. As a result, the volume fraction should only be used to determine how much fibre is in a beam [37].

\section{Conclusions}

The flexural performance of small-scale concrete beam specimens, using carbon textiles as the main reinforcement and discontinuous short fibres, was experimentally explored in this study to establish a structural design technique that may include textile reinforcement. Consequently, several sized textile-reinforced concrete beams with varied textile arrangements and sorts were investigated. Moreover, SRC beams were tested as control samples. Based on the facts and observations, the following conclusions were drawn:

- It was discovered that the shape and placement of textiles directly impact the binding amongst concrete and reinforcements. Lost rovings/tows result in a better connection owing to a rise in the interface amongst the concrete matrix and reinforcements, and consequently, an increase in the number of active filaments. Accordingly, the load capacity and deflection of the TRC beams with loose roving/tow were much higher.

- Textiles are corrosion-resistant, allowing for thinner cover thicknesses to be designed. However, because of the lower ability for transferring the stresses amongst the reinforcements and the concrete matrix, a thin cover thickness might cause shear and sudden failure.

- $\quad$ Because of the differences in textile and steel reinforcing characteristics, TRC beams behave differently from SRC beams in moment-curvature behaviour. The fundamental distinction between textiles and steel reinforcing qualities is the stress-strain performance.

- The ultimate loads and deflections of the TRC beam were around 50\% and 37\% larger than those of SRC beam for the similar reinforcement area, respectively.

- Overall, the flexural findings for TRC beam samples with various layouts reveal that textile reinforcement may adequately reinforce concrete beams as structural components.

Funding: This research was funded by of the Researchers Supporting Project number(RSP-2021/290), King Saud University, Riyadh, Saudi Arabia.

Data Availability Statement: The data presented in this study are available on request from the corresponding author. The data are not publicly available due to size of the research.

Acknowledgments: The author gratefully acknowledges the financial support of the Researchers Supporting Project number (RSP-2021/290), King Saud University, Riyadh, Saudi Arabia.

Conflicts of Interest: The author declares no conflict of interest.

\section{References}

1. Du, Y.; Zhang, X.; Zhou, F.; Zhu, D.; Zhang, M.; Pan, W. Flexural behavior of basalt textile-reinforced concrete. Constr. Build. Mater. 2018, 183, 7-21. [CrossRef]

2. Escrig, C.; Gil, L.; Bernat-Maso, E.; Puigvert, F. Experimental and analytical study of reinforced concrete beams shear strengthened with different types of textile-reinforced mortar. Constr. Build. Mater. 2015, 83, 248-260. [CrossRef]

3. Junes, A.; Larbi, A.S. An experimental and theoretical study of sandwich panels with TRC facings: Use of metallic connectors and TRC stiffeners. Eng. Struct. 2016, 113, 174-185. [CrossRef]

4. Bentur, A.; Mindess, S. Fibre Reinforced Cementitious Composites, 2nd ed.; CRC Press: New York, NY, USA, 2006.

5. Verbruggen, S.; Tysmans, T.; Wastiels, J. TRC or CFRP strengthening for reinforced concrete beams: An experimental study of the cracking behaviour. Eng. Struct. 2014, 77, 49-56. [CrossRef]

6. Mohammadhosseini, H.; Yatim, J.M.; Sam, A.R.M.; Awal, A.A. Durability performance of green concrete composites containing waste carpet fibers and palm oil fuel ash. J. Clean. Prod. 2017, 144, 448-458. [CrossRef]

7. Tysmans, T.; Adriaenssens, S.; Cuypers, H.; Wastiels, J. Structural analysis of small span textile reinforced concrete shells with double curvature. Compos. Sci. Technol. 2009, 69, 1790-1796. [CrossRef]

8. Tetta, Z.C.; Koutas, L.; Bournas, D.A. Textile-reinforced mortar (TRM) versus fiber-reinforced polymers (FRP) in shear strengthening of concrete beams. Compos. Part B Eng. 2015, 77, 338-348. [CrossRef] 
9. Mohammadhosseini, H.; Tahir, M.M.; Sam, A.R.M.; Lim, N.H.A.S.; Samadi, M. Enhanced performance for aggressive environments of green concrete composites reinforced with waste carpet fibers and palm oil fuel ash. J. Clean. Prod. 2017, 185, 252-265. [CrossRef]

10. Triantafillou, T.C.; Papanicolaou, C.G. Shear strengthening of reinforced concrete members with textile reinforced mortar (TRM) jackets. Mater. Struct. 2006, 39, 93-103. [CrossRef]

11. Sofiyev, A. Influences of shear stresses on the dynamic instability of exponentially graded sandwich cylindrical shells. Compos. Part B Eng. 2015, 77, 349-362. [CrossRef]

12. Papanicolaou, C.G.; Triantafillou, T.; Karlos, K.; Papathanasiou, M. Textile-reinforced mortar (TRM) versus FRP as strengthening material of URM walls: In-plane cyclic loading. Mater. Struct. 2006, 40, 1081-1097. [CrossRef]

13. Bournas, D.A.; Lontou, P.V.; Papanicolaou, C.G.; Triantafillou, T.C. Textile-reinforced mortar versus fiber-reinforced polymer confinement in reinforced concrete columns. ACI Struct. J. 2007, 104, 740.

14. Tetta, Z.C.; Koutas, L.; Bournas, D.A. Shear strengthening of full-scale RC T-beams using textile-reinforced mortar and textilebased anchors. Compos. Part B Eng. 2016, 95, 225-239. [CrossRef]

15. Gil, L.; Escrig, C.; Bernat-Maso, E. Bending performance of concrete beams strengthened with textile reinforced mortar TRM. In Key Engineering Materials; Trans Tech Publications Ltd.: Bach, Switzerland, 2014; Volume 601, pp. 203-206.

16. Mumenya, S.W.; Tait, R.B.; Alexander, M.G. Evaluation of toughness of textile concrete. Mater. Struct. 2010, 44, 279-289. [CrossRef]

17. Brockmann, T.; Brameshuber, W. Matrix development for the production technology of textile reinforced concrete (TRC) structural elements. In Proceedings of the 3rd International Conference on Composites in Construction, Vancouver Canada, 11-13 July 2005; pp. 1165-1172.

18. Barhum, R.; Mechtcherine, V. Influence of short dispersed and short integral glass fibres on the mechanical behaviour of textile-reinforced concrete. Mater. Struct. 2012, 46, 557-572. [CrossRef]

19. Cohen, Z.; Peled, A.; Pasder, Y.; Roye, A.; Gries, T. Effects of warp knitted fabrics made from multi-filament in cement-based composites. In Proceedings of the 1st International Conference in Textile Reinforced Concrete (ICTRC1), Aachen, Germany, 6 September 2006; pp. 23-32.

20. Häußler-Combe, U.; Hartig, J. Bond and failure mechanisms of textile reinforced concrete (TRC) under uniaxial tensile loading. Cem. Concr. Compos. 2007, 29, 279-289. [CrossRef]

21. Hegger, J.; Will, N.; Bruckermann, O.; Voss, S. Load-bearing behaviour and simulation of textile reinforced concrete. Mater. Struct. 2006, 39, 765-776. [CrossRef]

22. Hartig, J.; Häußler-Combe, U.; Schicktanz, K. Influence of bond properties on the tensile behaviour of Textile Reinforced Concrete. Cem. Concr. Compos. 2008, 30, 898-906. [CrossRef]

23. Hannant, D.J. Fibre-reinforced concrete. In Advanced Concrete Technology-Processes; Butterworth-Heinemann: Oxford, UK, 2003.

24. Hegger, J.; Voss, S. Investigations on the bearing behaviour and application potential of textile reinforced concrete. Eng. Struct. 2008, 30, 2050-2056. [CrossRef]

25. Alrshoudi, F.; Mohammadhosseini, H.; Tahir, M.M.; Alyousef, R.; Alghamdi, H.; Alharbi, Y.; Alsaif, A. Drying shrinkage and creep properties of prepacked aggregate concrete reinforced with waste polypropylene fibers. J. Build. Eng. 2020, $32,101522$. [CrossRef]

26. Yin, S.P.; Lü, H.L.; Xu, S.L. Properties and calculation of normal section bearing capacity of RC flexural beam with skin textile reinforcement. J. Cent. South Univ. 2013, 20, 1731-1741. [CrossRef]

27. Hussien, O.H.; Ibrahim, A.M.; Abd, S.M. Improving Flexural Behavior of Textile Reinforced Concrete One Way Slab by Removing Weft Yarns with Different Percentages. Civ. Eng. J. 2018, 4, 2903. [CrossRef]

28. Ortlepp, R. Efficient Adaptive Test Method for Textile Development Length in TRC. Adv. Civ. Eng. 2018, 2018, 4650102. [CrossRef]

29. Alrshoudi, F.; Mohammadhosseini, H.; Alyousef, R.; Alghamdi, H.; Alharbi, Y.R.; Alsaif, A. Sustainable use of waste polypropylene fibers and palm oil fuel ash in the production of novel prepacked aggregate fiber-reinforced concrete. Sustainability 2020, 12, 4871. [CrossRef]

30. Contamine, R.; Larbi, A.S.; Hamelin, P. Tensile identification of textile reinforcement concrete behaviour. In Proceedings of the International RILEM Conference on Material Science; RILEM Publications SARL: Aachen, Germany, 2010; pp. 105-110.

31. Mohammadhosseini, H.; Alrshoudi, F.; Tahir, M.M.; Alyousef, R.; Alghamdi, H.; Alharbi, Y.R.; Alsaif, A. Performance evaluation of novel prepacked aggregate concrete reinforced with waste polypropylene fibers at elevated temperatures. Const. Build. Mater. 2020, 259, 120418. [CrossRef]

32. Abdulmajeed, A.A.; Närhi, T.O.; Vallittu, P.K.; Lassila, L.V. The effect of high fiber fraction on some mechanical properties of unidirectional glass fiber-reinforced composite. Dent. Mater. 2011, 27, 313-321. [CrossRef]

33. Mohammadhosseini, H.; Alrshoudi, F.; Tahir, M.M.; Alyousef, R.; Alghamdi, H.; Alharbi, Y.R.; Alsaif, A. Durability and thermal properties of prepacked aggregate concrete reinforced with waste polypropylene fibers. J. Build. Eng. 2020, 32, 101723. [CrossRef]

34. Alyousef, R.; Mohammadhosseini, H.; Alrshoudi, F.; Alabduljabbar, H.; Mohamed, A.M. Enhanced performance of concrete composites comprising waste metalised polypropylene fibres exposed to aggressive environments. Crystals. 2020, 10, 696. [CrossRef]

35. Mohammadhosseini, H.; Ngian, S.P.; Alyousef, R.; Tahir, M.M. Synergistic effects of waste plastic food tray as low-cost fibrous materials and palm oil fuel ash on transport properties and drying shrinkage of concrete. J. Build. Eng. 2020, 102826. [CrossRef] 
36. Alrshoudi, F.; Mohammadhosseini, H.; Alyousef, R.; Alabduljabbar, H.; Mustafa Mohamed, A. The impact resistance and deformation performance of novel pre-packed aggregate concrete reinforced with waste polypropylene fibres. Crystals 2020, 10, 788. [CrossRef]

37. Mohammadhosseini, H.; Awal, A.S.M.A. Physical and mechanical properties of concrete containing fibers from industrial carpet waste. Int. J. Res. Eng. Technol. 2013, 2, 464-468. 